\title{
Fabrication and evaluation of a medicated hydrogel film with embelin from Embelia ribes for wound healing activity
}

\author{
Hiral Shrimali ${ }^{1}$, Uttam Kumar Mandal ${ }^{2 \dagger}$, Manish Nivsarkar $^{3+}$ and Neeta Shrivastava ${ }^{3^{*}}$
}

\begin{abstract}
Background: There has been huge interest among the researchers to incorporate a medicinally active compounds in hydrogel sheets for effective treatment of wound healing. This research work involves development and evaluation of medicated hydrogel sheet incorporated with embelin which has both antimicrobial and wound healing activity. Embelin was isolated from the fruits of Embelia ribes and characterized by various physical and analytical methods like melting point, UVNIS spectroscopy, and HPTLC. The hydrogel sheets containing polyvinyl alcohol and polyethylene glycol was prepared by freeze-thaw technique, where isolated embelin was successfully incorporated within the sheet. The prepared hydrogel sheets were further characterized by in vitro drug release study, swelling capacities, gel fraction, water vapor transmission rate (WVTR), mechanical strength, and scanning electron microscopy (SEM) study. Finally, the optimized hydrogel with embelin was evaluated for its wound healing efficacy in vivo using excision wound model on Sprague-Dawley rats.

Results: The optimized hydrogel sheet had a composition of 5\% PEG 400 and 10\% PVA. It had acceptable in physico-chemical properties with respect to swelling capacities, gel fraction, water vapor transmission rate (WVTR), and mechanical strength The release of the drug from hydrogel followed zero order kinetics with more than $80 \%$ drug release within $12 \mathrm{~h}$. The in vivo studies on the Sprague-Dawley showed faster healing process with embelin loaded hydrogels as compared to the control and market formulation.
\end{abstract}

Conclusions: Sheet hydrogel with $0.2 \%$ embelin was found to have huge potential for moist wound healing activity.

Keywords: Wound healing, Hydrogel sheet, Polyvinyl alcohol, Polyethylene glycol, Embelin

\section{Background}

Apart from financial burden, wounds and particularly chronic wounds (that do not heal within 3 months) causes a lot of sufferings to patients in their social life. In the USA, chronic wound related complications affect 5.7 million patients, which costs an estimated 20 billion dollars annually [1]. Increased number of geriatric patients together with a huge volume of surgeries and increased awareness about wound care products among the presents have resulted such a steep growth of this

\footnotetext{
* Correspondence: neetashrivastavaperd@gmail.com

Uttam Kumar Mandal and Manish Nivsarkar are co-authors.

+Uttam Kumar Mandal and Manish Nivsarkar contributed equally to this work.

${ }^{3}$ B.V. Patel Pharmaceutical Education and Research Development (PERD)

Centre, Ahmedabad 380054, India

Full list of author information is available at the end of the article
}

market. According to the Global Wound Care Market report, the Wound Care Market accounted a value of $\$ 18.22$ billion in 2016 and is projected to reach a value $\$ 26.24$ billion at the end of 2023. According to another recent past market survey with forecast for world market of wound management products until the year 2022, demand for wound management products is expected to grow at a compound annual growth rate (CAGR) of 6.7\% (https://www.psmarketresearch.com/press-release/ wound-care-market). As per that survey, China will form the fastest expanding wound management; however, the significant market growth will be experienced by North America (CAGR 7.1\%), Asia pacific (CAGR 7.2\%), Europe, and other regions. This has obviously drawn huge attention to the pharmaceutical manufacturers to develop patient-friendly wound care products. 
In general, a wound occurs when the integrity of any tissue is compromised (e.g., skin breaks, muscle tears, burns, or a bone fracture). A wound may be caused as a result of an injury from accident, a surgical procedure, an infectious disease or an underlying pathological condition [2]. So, it becomes very essential to manage such kind of wounds which may be achieved by the use of dressings. Traditionally, used dressings like cotton swabs and cotton gauzes suffer from the difficulties like they make the wound dry and also their removal is painful; thus, there has been always a genuine need for modern dressings which facilitate wound healing rather than just cover it. The modern dressings include hydrocolloids, films, alginate dressings, and hydrogels termed as occlusive dressings [3]. Apart from hydrogels, the other dressings have limitations like the inability to absorb excess wound exudates, adhesive may strip away newly formed epithelium, always require secondary dressing, and impermeable to oxygen. Thus, there is a need for a dressing which could eliminate these limitations or rather minimizes them.

Hydrogels are a class of polymer materials that can absorb large amounts of water without dissolving. They are cross-linked polymeric gels that have water-holding and non-adhering properties. They work on the principle of moist wound healing proposed by George Winter [4]. This has several advantages like decreased dehydration and cell death, increased angiogenesis, enhanced autolytic debridement, increased re-epithelialization, and decreased pain [5]. Few sheet hydrogels are available in international markets like Nu-gel ${ }^{\circ}$, Vigilon ${ }^{\circ}$, Flexigel ${ }^{\circ}$, and Aquamatrix ${ }^{\circ}[6]$, but they are all composed without any medically active agents in them. This has created huge interests among the researchers to incorporate a medicinally active compound in these hydrogel sheets. The present research work is based on the same approach where an attempt was made to prepare a sheet hydrogel containing a medicinally active compound embelin which was extracted form Embelia ribes, purified and characterized before the formulation. Embelia ribes is woody shrub belongs to the family Myrsinaceae, which is distributed in less densed moist deciduous forests of the Western Ghats, India, Sri Lanka, Malaysia, and South China [7]. It is commonly known as bidang, vidang, vavding, or vaya vidang in the Indian Ayurvedic system. Embelin, the active constituent this plant, has anticonvulsant [8], antibacterial [9], antioxidant [10], and antifertility activities [11]. Apart from these activities, embilin has been reported for wound healing and antimicrobial activities [12, 13], and accordingly it was selected as active ingredient for this work.

\section{Methods}

\section{Materials}

Embelia ribes fruits were collected from the local market of Ahmedabad, India and authenticated by botanist at B.
V. Patel PERD Centre, Ahmedabad, India. The reference standard was obtained from RRL (Regional Research Laboratory) Jammu, India. Polyvinyl alcohol (MW 1, 95, 000) and polyethylene glycol 400 were purchased from Sigma-Aldrich Co. (St. Louis, MO, USA) and Merck Limited (Mumbai, India), respectively. Petroleum ether, sodium bicarbonate, sodium di-hydrogen orthophosphate, potassium chloride, and sodium chloride were purchased from Qualigens Fine Chemicals, Mumbai, India. Calcium chloride was purchased from Merck Ltd, Mumbai, India. All the reagents were used as supplied by the suppliers without any further purification.

\section{Isolation of embelin}

The pure embelin was isolated from E. ribes by the method developed in our laboratory. Briefly, the fruits of $E$. ribes were powdered. The weighed amount of powdered drug $(100 \mathrm{~g})$ was taken in a conical flask. It was extracted with Petroleum ether for 4-5 times $(4 \times 100 \mathrm{ml})$. The extraction was carried out with intermittent heating at temperatures not exceeding $50{ }^{\circ} \mathrm{C}$. The extract was filtered using a Whitman filter paper. After the complete extraction, the filtrates were pooled together and kept at $4{ }^{\circ} \mathrm{C}$ overnight. The obtained orange colored precipitate was washed with petroleum ether to remove the fatty impurities and further recrystallized with diethyl ether.

\section{Characterization of embelin powder}

The purity of the obtained embelin powder was confirmed by the following:

\section{Melting point}

For the determination of melting point, the isolated embelin was filled in the capillary tube which was sealed at one end. A similar procedure was followed for reference standard too. The capillary tubes containing the samples were placed in the Veego melting point apparatus and the instrument was switched on. The temperature at which the samples melted was noted.

\section{UV-Vis spectroscopy}

For the UV analysis, a sample of isolated embelin was prepared in methanol for which it was dissolved in methanol. The spectra of the resultant solution was taken using Shimadzu UV-2450. Similarly, a solution of the reference standard was also prepared in methanol and was subjected to spectral analysis.

\section{Mass spectroscopy}

The analysis of the mass of the isolated compound was performed by Mass Spectrometer (API 2000, AB Sciex) to confirm the identity of the compound. The reported molecular weight of embelin is 294 (Merck Index, page 3513). 


\section{High-performance thin layer chromatography}

A sample solution of the reference standard and the isolated compound were subjected to HPTLC study. The samples were applied on the TLC plates using Linomat $\mathrm{V}$ auto sampler. The plate was developed in a mobile phase constituting of n-propanol: n-butanol: ammonia $(4 \mathrm{~N})$ in a ratio of 7:1:2 v/v in a twin trough TLC chamber which was pre-saturated with the mobile phase. The developed plate was dried and then was scanned in the CAMAG scanner using the software WINCATS. Spectra of reference standard and isolated embelin thus obtained were compared by spectral overlay method.

\section{High-performance liquid chromatography}

To further ensure the purity of the isolated embelin, and also for analysis of the released embelin from the formulation, a HPLC method was developed using a $\mathrm{C}_{18}$ (Gemini Su, $250 \times 460 \mathrm{~mm}, 5 \mu$ ) reverse phase column. The various ratios of methanol:water mobile phase were tried to resolve the peak shape and purity. Out of the various ratios, the mobile phase consisting of 80:20 (v/v) ratio of methanol:water (adjusted to $\mathrm{pH}-9.02$ using aq. ammonia) at a flow rate of $1 \mathrm{ml} / \mathrm{min}$ (PU 2080 plus pump) got good results and was selected for further experimentation. The samples for analysis were prepared in the mobile phase prior to the analysis. The column was allowed to pre saturate with the mobile phase; thereafter, the samples were injected using an autosampler (Jasco AS 950). The peak was detected using a photodiode array detector (Jasco MD 2010 plus multi wavelength detector).

\section{Preparation of hydrogel sheets}

The hydrogel sheets were prepared by freeze-thaw (F-T) technique [14] according to the compositions mentioned in Table 1. PVA was used as a gel forming polymer. PVA and PEG 400 were dissolved in alkaline distilled water ( $\mathrm{pH}$ 7.7). The solution was heated on a water bath for $1 \mathrm{~h}$ with continuous stirring to dissolve the PVA completely. Then embelin powder $(0.2 \%)$ was added in it and the final solution was poured into a Petri dish plate of $8 \mathrm{~cm}$ in diameter. The plate was frozen at $-80^{\circ} \mathrm{C}$ for $16 \mathrm{~h}$ and then thawed at room temperature for $8 \mathrm{~h}$ for three consecutive cycles which resulted in the final hydrogel sheet $[15,16]$.

Table 1 Various compositions of PVA and PEG 400 used to prepare the hydrogel sheets

\begin{tabular}{llllllllll}
\hline Ingredients & I & II & III & IV & V & VI & VII & VIII & IX \\
\hline PVA & 8 & 10 & 12 & 8 & 10 & 12 & 8 & 10 & 12 \\
PEG 400 & 2.5 & 2.5 & 2.5 & 5 & 5 & 5 & 7.5 & 7.5 & 7.5 \\
Water qs & 100 & 100 & 100 & 100 & 100 & 100 & 100 & 100 & 100 \\
\hline
\end{tabular}

*Each ingredient was added w/w \%

\section{Characterization of hydrogel sheets \\ Gel fraction}

After three freeze-thaw (F-T) cycles, the hydrogel sheets were dried for $6 \mathrm{~h}$ at $50{ }^{\circ} \mathrm{C}$ in an oven $\left(W_{o}\right)$. They were then soaked in distilled water for $24 \mathrm{~h}$ until a constant weight was reached. The hydrogels were then dried again at $50{ }^{\circ} \mathrm{C}$ in oven $\left(W_{e}\right)$. The gel fraction percentage was calculated by the following equation [17].

$$
\text { Gel fraction }=\left(\frac{W_{e}}{W_{0}}\right) \times 100
$$

where $W_{o}$ and $W_{e}$ are the weights of hydrogel samples dried for $6 \mathrm{~h}$ at $50{ }^{\circ} \mathrm{C}$ before and after soaking, respectively.

\section{Swelling index}

The pieces of hydrogel sheets $(1 \mathrm{~cm} \times 1 \mathrm{~cm})$ were dried at $60{ }^{\circ} \mathrm{C}$ in oven for $12 \mathrm{~h}\left(W_{a}\right)$. They were then soaked in a simulated wound fluid (SWF) $\mathrm{pH} 7.7$ at $37{ }^{\circ} \mathrm{C}\left(W_{s}\right)$. The swelling index percentage was calculated using the following equation $[17,18]$.

$$
\text { Swelling index }=\left(\frac{W_{s}}{W_{a}}\right) \times 100
$$

where $W_{a}$ and $W_{s}$ were the weights of hydrogel samples dried for $12 \mathrm{~h}$ at $60{ }^{\circ} \mathrm{C}$ and soaked in PBS at $37{ }^{\circ} \mathrm{C}$, respectively.

\section{Water vapor transmission rate}

The water vapor transmission tests were performed using the JIS 1099A standard method [16]. A round piece of hydrogel was mounted on the mouth of a cup $\left(1.8 \mathrm{~cm}\right.$ in diameter) containing $12.8 \mathrm{~g}$ of $\mathrm{CaCl}_{2}$ and placed in an incubator of $75 \% \mathrm{RH}$ at $40{ }^{\circ} \mathrm{C}$.

The water vapor transmission rate (WVTR) was determined as follows:

$$
\operatorname{WVTR}\left(\mathrm{g} / \mathrm{m}^{2} \times \text { day }\right)=\left(\frac{W_{2}-W_{1}}{S}\right) \times 100
$$

where $W_{1}$ and $W_{2}$ were the weights of the whole cup at the first and second hours, respectively, and $S$ was the transmitting area of the sample.

\section{Surface morphology}

The surface morphology of the samples was investigated by scanning electron microscopy (SEM JSM-5610 LV). After $24 \mathrm{~h}$ of dissolution study, the hydrogel sheets were dehydrated by drying them in oven and were then subjected to SEM study [15].

\section{Mechanical properties}

The tensile strength and breaking elongation of hydrogels were determined using a tensile test machine (QTS 


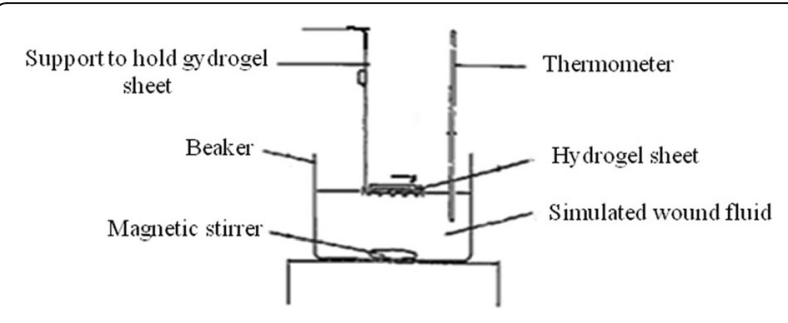

Fig. 1 Experimental set up for in vitro drug release study

Brookefield Texture Analyzer). After three F-T cycles, the hydrogel sheets were cut into a rectangular shape (6- $\mathrm{cm}$ long and $1.5-\mathrm{cm}$ wide), and they were subjected to the mechanical analysis at a stretching rate of $60 \mathrm{~mm} / \mathrm{min}$ with an initial load of $5 \mathrm{~g}$ [18].

\section{In vitro drug release study}

In vitro drug release of the F-T hydrogel sheets was carried out using a modified dissolution test instrument (Fig. 1) designed in-house. The method followed was total immersion method [19]. Hydrogel sheets were immersed with the help of a support in a beaker containing $20 \mathrm{ml}$ of simulated wound fluid (142 mM sodium chloride and $2.5 \mathrm{mM}$ calcium chloride in water). The beaker was placed on a magnetic stirrer and was magnetically agitated at $75 \mathrm{rpm}$ [20]. Samples of $1 \mathrm{ml}$ were withdrawn from the beaker at specified time intervals over a period of $24 \mathrm{~h}$ and were replaced by equal volume of fresh SWF. The amount of drug released with respect to time was determined by UV-Vis spectrophotometer at $290 \mathrm{~nm}$ against a standard curve of embelin in simulated wound fluid in the concentration range of 1 to $10 \mu \mathrm{g} / \mathrm{ml}$. The study was performed in six replicates.

\section{In vivo studies}

In vivo studies on rats were carried out after to evaluate the wound healing activity of the optimized hydrogel formulation. Study was started after getting the approval from Institutional Animal Ethical committee (Approval No: PERD/IAEC/2010/001). Six male Sprague-Dawley rats, weighing approximately 200-300 g, were procured from animal house of PERD center, Ahmedabad. The rats were housed in the animal house and were kept in standard sized metallic cages (3 rats/cage) in a wellventilated room, and at a temperature of about $26-28{ }^{\circ} \mathrm{C}$. They were acclimatized to the animal house condition for 7 days during which they were allowed to free access of water and food. The dorsal abdominal area of the animals was shaved in the direction of tail to head. Animals were anesthetized using diethyl ether and four excision wounds of full thickness, each $1.0 \mathrm{~cm}$ (circular area $=78.5 \mathrm{~mm}^{2}$ ) in diameter and $0.2 \mathrm{~mm}$ in depth along the marked area using a surgical blade, were created on each animal. The area for excision was marked using a marker. The wounds were cleaned with a sterile cotton prior to the reading and treatments.

The excised wounds were covered with the optimized hydrogel dressings containing embelin and were fixed with elastic adhesive tape (Medi grip). Moisturex ${ }^{\oplus}$ cream (Ranbaxy) and a blank hydrogel sheet (without embelin) were used as standard and control samples, respectively.

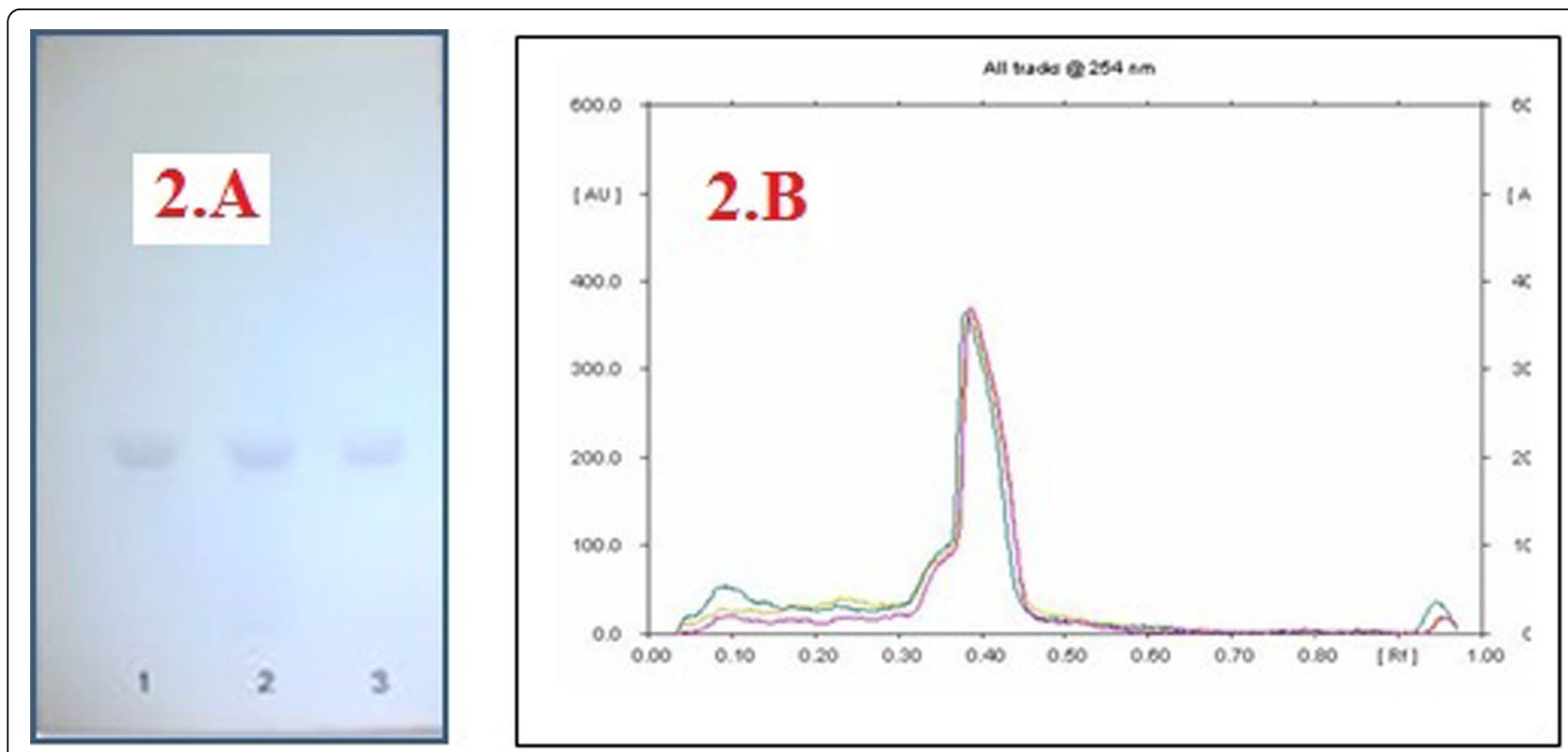

Fig. 2 a Co-chromatography of embelin with test sample (1) and reference std (2 and 3) and b HPTLC chromatogram of reference standard (pink) and isolated embelin (green and yellow) 
Moisturex cream was chosen as standard sample for its reported wound healing activity (https://www.mims. com/india/drug/info/moisturex/moisturex\%20cream).

Another reason of this selection was due to nonavailability of commercial medicated hydrogel sheet.

Dressings were changed every day. The wound healing rate was measured at the 3rd, 6th, 9th, 12th, and 15th day post-operation in terms of percent wound contraction [21]. The area of the wound was measured by tracing the size of the wound on a butter paper, and then the area was measured using a graph paper. The grouping of the wounds on the animals was done randomly into four groups: a, normal control (treated with saline); b, hydrogel with drug (embelin); c, hydrogel without drug and d: marketed preparation (Moisturex ${ }^{\bullet}$ cream). The dressing on the wound was shifted from animal to animal in a clockwise direction on the back of the rat as a, b, c, d; d, a, b, c; c, d, a, b, and likewise; this shifting of the dressing was done in order to avoid any biasness in the position of the wounds which might affect the healing process. The wound contraction was measured by the formula mentioned below:

$$
\% \text { wound contraction }=\left(\frac{A_{0}-A_{t}}{A_{0}}\right) \times 100
$$

where $A_{o}$ is wound size (area) at the initial time and $A_{t}$ is wound size (area) at time $t$.

After the experiment, the animals were killed by cervical dislocation method followed by sacrification, and the carcasses were incinerated.

\section{Results and discussion}

The purity and identity of the isolated embelin were compared against the reference standard. The crystallization of the embelin from $E$. ribes yielded $97 \%$ purity determined by HPLC. The UV-Vis spectral overlap of sample and reference peaks at the start, middle, and end of peaks were compared by HPTLC (Fig. 2). The UV spectra showed an absorption maximum at $289 \mathrm{~nm}$ which was found to be similar to reference standard $\left(\lambda_{\max }, 290 \mathrm{~nm}\right)$. The melting point was found to be $142-144{ }^{\circ} \mathrm{C}$ against the reported value of $142-143{ }^{\circ} \mathrm{C}$, and the mass spectra of isolated compound showed (M-1) $\mathrm{m} / \mathrm{z}$ ratio of 293.4 against the reported molecular weight of embelin 294.5. Thus, the isolated compound was confirmed as embelin and the same was used for further experimentation.

The hydrogel sheets using different compositions of PVA and PEG 400 (Table 1) were prepared by freezethaw cross linking after three cycles and were subjected to the various evaluation parameters as mentioned in the methodology section. The gel fraction of the prepared hydrogels was found to be in the range of 55-95\% (Fig. 3). The gel fraction provides the extent to which

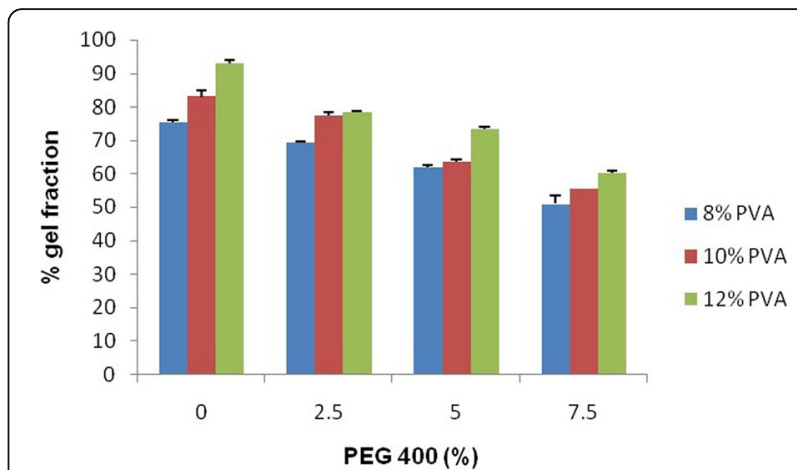

Fig. 3 Effect of concentration of PEG 400 and PVA on percentage gel fraction of the hydrogel sheets, $n=3$, mean \pm SEM

the polymer chains have cross-linked with each other. In other words, the more the gel fraction the more is its crosslinking ability, and thus the more is its mechanical strength. It was found that as the concentration of PVA increased, the gel fraction of the sheet hydrogels also increased proportionately. This may be attributed to the increased crosslinking of polymer chains with the increasing concentration of polymer. The addition of PEG within the formulation decreased the percent gel fraction of the sheet hydrogel suggesting that it is somewhere interfering with the cross linking of PVA, and thereby decreasing the gel fraction.

The swelling index of the hydrogels was found to be a maximum of $372 \%$ as shown in Fig. 4 . The swelling of a sheet hydrogels becomes very important in case of heavily exuding wounds. This helps in preventing the accumulation of the wound fluid in the wound bed, and thereby decreasing the chances of any bacterial contamination [22,23]. It is observed from the graph that as the concentration of PVA increased, \% swelling ratio also decreased. As an explanation, the higher concentration of polymer increases the cross linking, and thereby decreasing the porosity within the gel structure which results in a decrease in \% swelling ratio. Addition of PEG

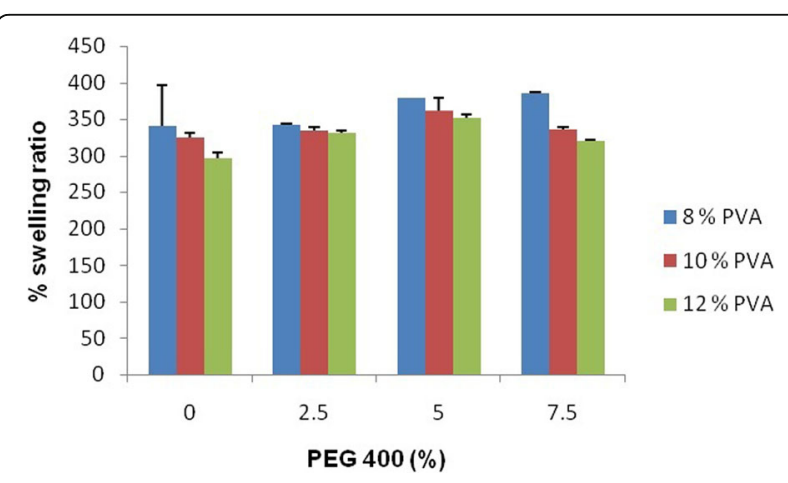

Fig. 4 Effect of concentration of PEG 400 and PVA on percentage swelling ration of the hydrogel sheets, $n=3$, mean \pm SEM 


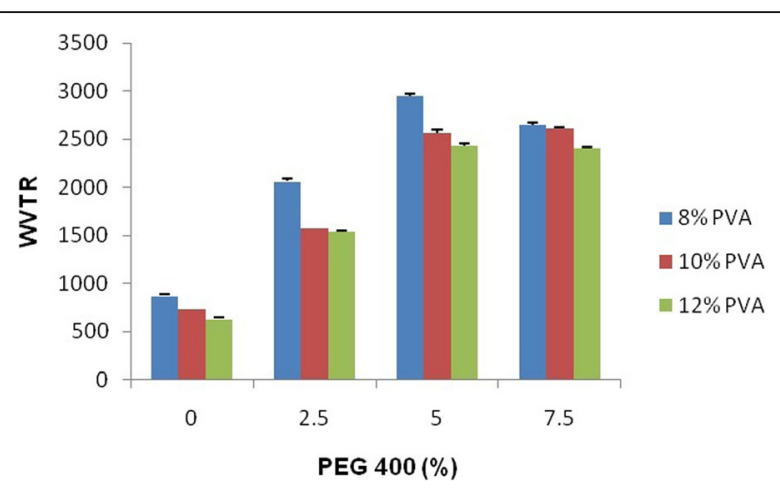

Fig. 5 Effect of concentration of PEG 400 and PVA on percentage WVTR of the hydrogel sheets, $n=3$, mean \pm SEM

400 to the PVA solution was found to increase the \% swelling ratio up to $5 \% \mathrm{w} / \mathrm{w}$ concentration of PEG 400 . As explained in the gel fraction study, PEG 400 hinders the process of polymer cross-linking, produces a lesser cross-linked hydrogel matrix as compared to the PVA alone and makes the hydrogel sheets more porous as compared to only PVA hydrogel sheets.

The WVTR of the various formulations prepared by the F-T method using PEG 400 is shown in Fig. 5. The WVTR of the hydrogel sheets containing only PVA is very less as compared to the hydrogel sheets prepared by PVA and PEG 400. PEG 400 as an interference to PVA cross-linking helps to maintain porosity within the hydrogel sheets up to a certain concentration. The hydrogels are the cross-linked polymers. Thus, the extent of its cross-linking determines its ability to transmit the vapor or the air to and fro from the hydrogel. The WVTR plays an important role to keep the wound bed moist. If the WVTR of the hydrogel is more, it makes the wound bed very moist, whereas low WVTR makes the wound bed dry. Thus, a hydrogel dressing should have an optimum WVTR, so that it can provide proper moistening to the wound bed, and thus helps in enhancing the healing process. The WVTR of an ideal wound dressing is reported to be $2000-2500 \mathrm{~g} / \mathrm{m}^{2}$ day [16], our hydrogel sheets (formulation IV to IX) also fell under that range [24].

From the above three parameters, it was found that the hydrogels containing 10\% PVA irrespective of the PEG 400 concentration, had a desirable gel fraction (63\%), swelling ratio $(318.6 \%)$, and WVTR $\left(2503 \mathrm{~g} / \mathrm{m}^{2}\right.$ day). So, then to decide the optimum composition of PEG 400, the hydrogel sheets with $10 \%$ PVA at $2.5,5$, $7.5 \% \mathrm{w} / \mathrm{w}$ concentration of PEG 400 were further tested for their tensile strength. Figure 6 shows the mechanical strength of the hydrogel sheets in terms of their tensile strength and percentage elongation at break point. It was found that with the increase of PEG 400 concentration, tensile strength and the elongation at break of the hydrogel sheets also increased. It suggests that the incorporation of PEG 400 makes the hydrogel sheets tougher and more elastic. The hydrogel sheets containing 10\% w/w PVA, 5\% $\mathrm{w} / \mathrm{w}$ PEG 400, and $0.2 \% \mathrm{w} / \mathrm{w}$ embelin resulted an optimum tensile strength $\left(>250 \mathrm{~g} / \mathrm{cm}^{2}\right)$ and percentage elongation at break point ( $>800 \%$ ), and thus was chosen for the further studies.

The in vitro release studies were performed on three compositions of hydrogel sheets containing 10\% PVA each with three different composition of PEG 400 (2.5, 5, and $7.5 \% \mathrm{w} / \mathrm{w})$. Figure 7 represents the release profile of embelin from the hydrogel sheets. Other than the hydrogel sheet with 10\% PVA and 7.5\% PEG 400, the remaining two formulations produced more than $80 \%$ drug release at $12 \mathrm{~h}$. However, all of them showed about $90 \%$ of embelin release at the end of $24 \mathrm{~h}$. The release followed a linear pattern and was found to follow zero order kinetics up to $12 \mathrm{~h}$.

Figure 8 represents the surface morphology of the optimized hydrogel formulation before and after the

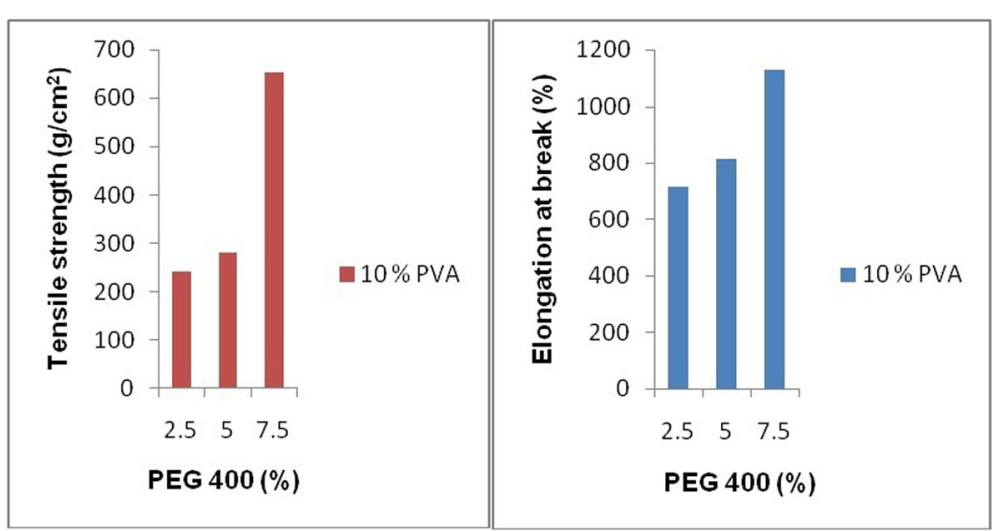

Fig. 6 Effect of concentration OF PEG 400 on the tensile strength and percentage elongation at break of the hydrogel sheets, $n=3$, mean \pm SEM 


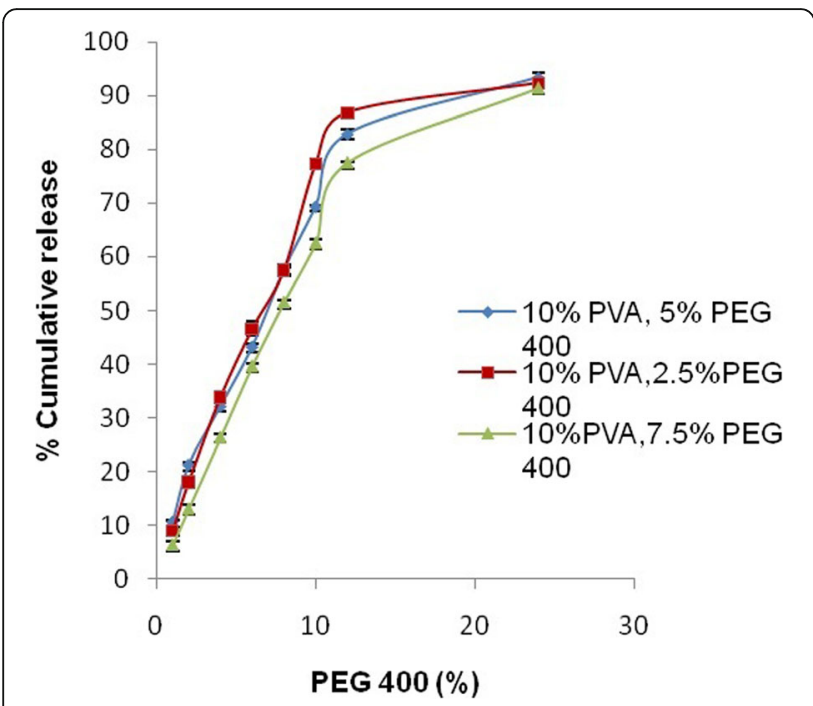

Fig. 7 In vitro drug release from hydrogel sheets

dissolution studies up to $24 \mathrm{~h}$. It is observed that Fig. $8 \mathrm{~b}$ (after dissolution) shows more porous nature as compared to Fig. 8a (before dissolution). Being soluble in nature, PEG 400 helps in channel formation within the hydrogel sheets during dissolution and embelin is released into the dissolution medium which ultimately makes gel matrix porous in nature.

The estimation of in vivo efficacy of the developed hydrogel was performed using the full-thickness excision wound model. The optimized hydrogel sheet with a composition of $10 \%$ PVA, $5 \%$ PEG 400, and $0.2 \%$ embelin was used for this study. Figure 9 shows the photographs of the wounds treated with the various dressings and the control wounds (untreated). The results obtained on the 3rd day post-treatment showed $30-40 \%$ reduction in wound size
(Fig. 10) in all the animals. However, it was noticed that the wounds treated with the medicated hydrogel showed a maximum reduction in wound area as compared to other groups. It was also observed that the swelling around the wound area decreased in all the animals on the 3rd day after the initiation of the treatment. As expected, the wounds treated with drug loaded hydrogels showed no sign of dry scar formation, rather the wounds were moist, which justify the better wound healing of that treatment as compared to the control and marketed formulation. At the end of 6th day post-treatment, the hydrogel treated wounds showed a formation of a thin epidermis without any scar infection. This formation of epidermis was only found in the wounds treated with hydrogels which can be attributed to the property of the hydrogel to maintain a moist environment in the wound region. At the end of 9th day post-treatment, all the wounds in group "b" (medicated hydrogel) showed $90 \%$ reduction in wound area and the epidermis layer showed thickening. The control and marketed groups also showed a reduction in wound area but the epidermis was not completely formed. It is mentioned in the literature [23] that during the initial phases of healing one needs a constant flow of the growth factors and nutrients in the wound area so as to initiate the epithelization and enhance the formation of granulating tissue [24]. The wound healing process needs an initial early re-epithelialization and granulation tissue formation that was confirmed by our work with the embelin containing optimized hydrogel sheet. This hydrogel sheet was found to be very much useful for the rapid initialization of wound healing process.

The observed results suggest that the hydrogels help in enhancing the healing process by creating a moist environment. It is observed from the results that at the end of 12th and 15th days post-treatment, all the treated groups showed a similar contraction of the wound area.
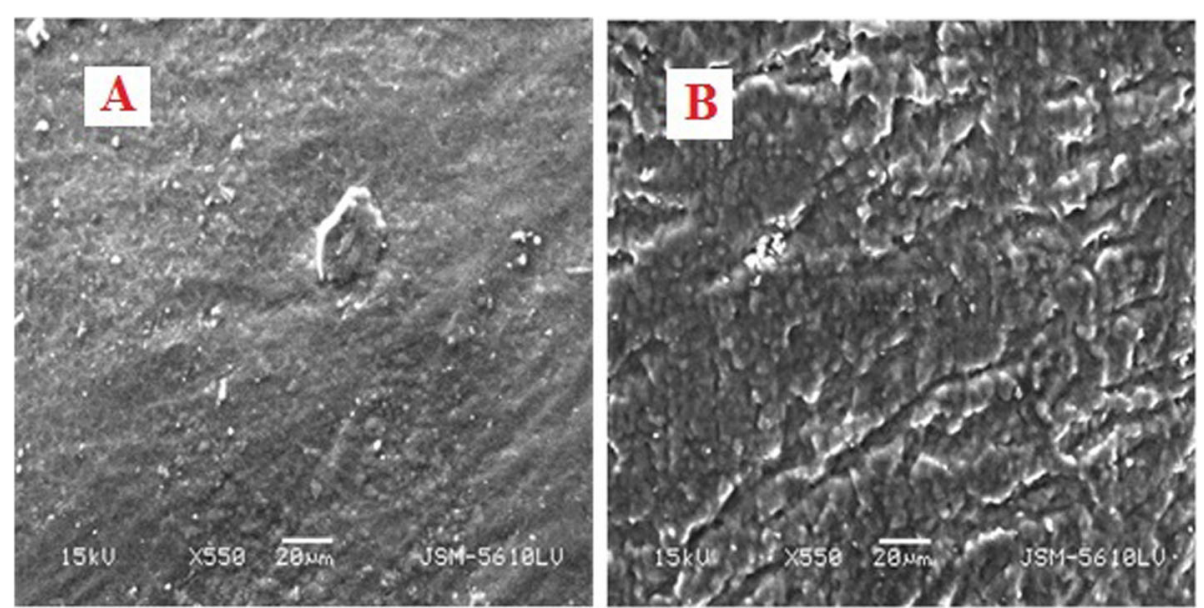

Fig. 8 SEM micrographs: hydrogel containing 10\% w/w PVA, 5\% w/w PEG 400, and 0.2\% w/w embelin. a Before and b after dissolution 


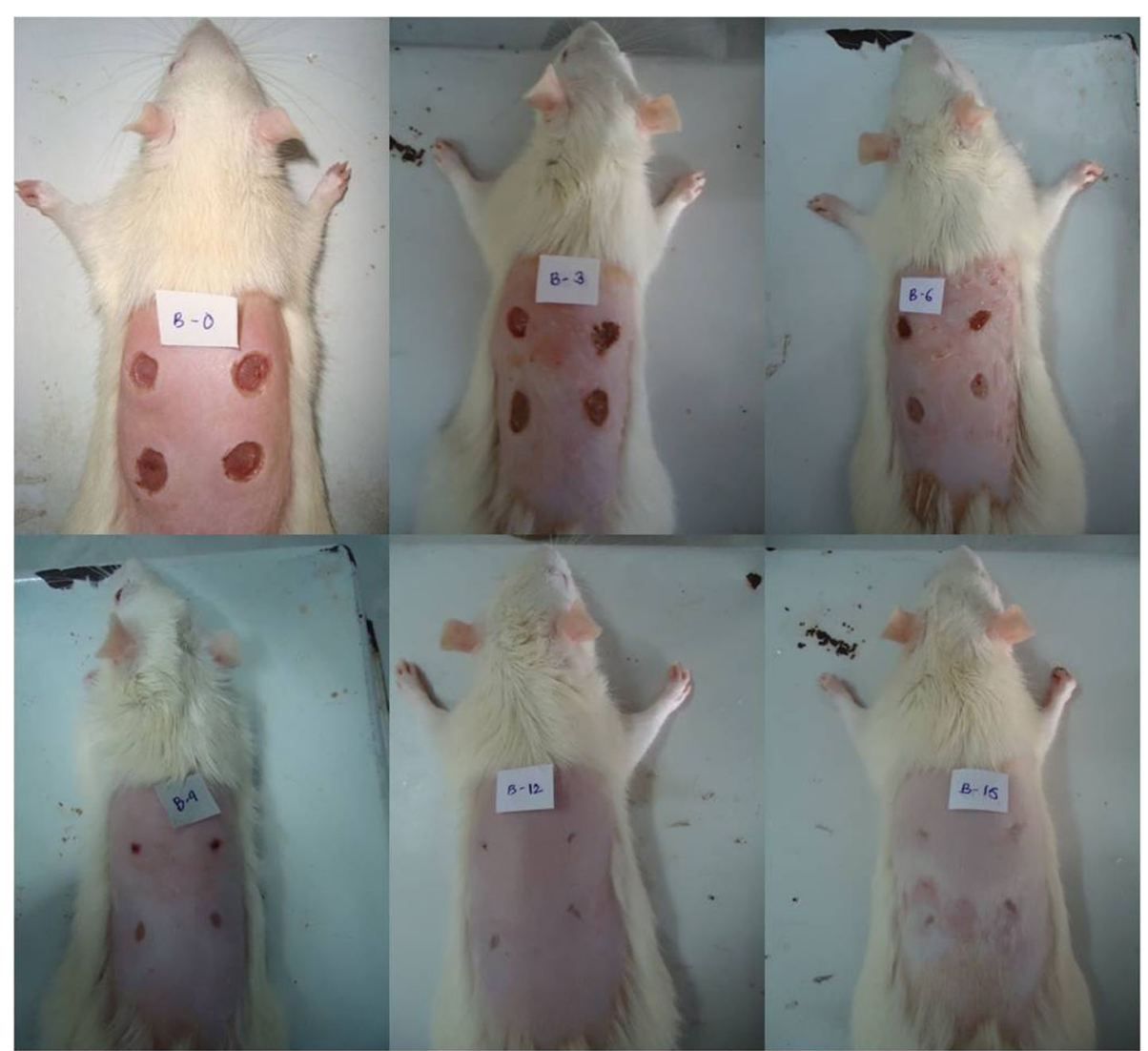

Fig. 9 Photographs of wound treated with (a) sterile gauze, (b) hydrogel with $0.2 \%$ embelin, (c) hydrogel without any drug, and (d) marketed product at $\mathbf{a} 0$ days, $\mathbf{b} 3$ days, $\mathbf{c} 6$ days, $\mathbf{d} 9$ days, e 12 days, and $\mathbf{f} 15$ days of post-operation

However, the appearance of the wounds treated by the medicated hydrogel (group b) were uniform, cleaner, and healthy as compared to all the other groups (a, c, and d). Thus, we can infer from these results that medicated hydrogels are good for initial wound healing process as they initiate the healing process faster.

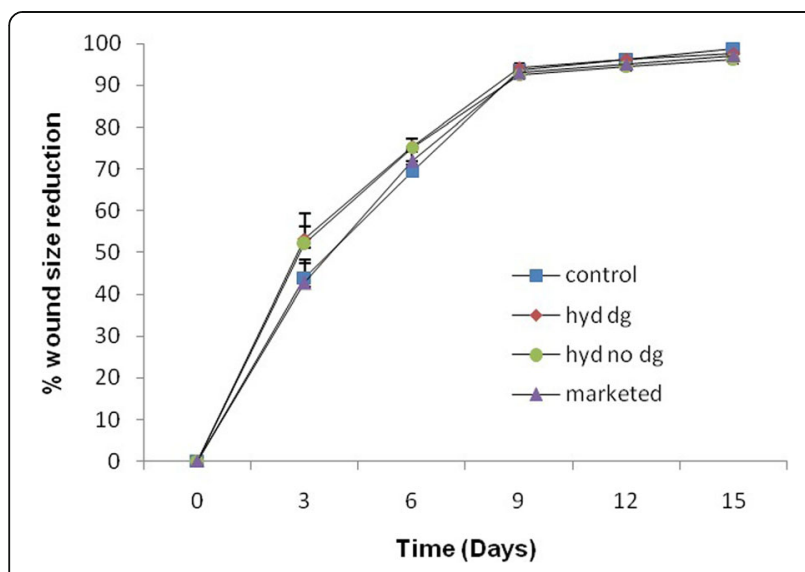

Fig. 10 Percentage wound size reduction of the control, hydrogel with drug, hyrdogel without drug, and marketed product, $n=6, p<0.05$
Day-wise comparative healing for medicated hydrogel sheet against standard or control formulation is summarized in Table 2. In summary, it was found that wound healing is a complex process and the key points through healing rate is increased by providing an environment suitable for healing in the initial stages itself. It is known that wound repair must occur in a physiologic environment which is conducive to tissue repair and regeneration. In addition, increased metabolic demands are made by the inflammation and cellular activity in the healing wound, which may require increased protein or amino acids, vitamins, and minerals. Thus, due to all these reasons, one needs to have a moist environment in the initial stages of wound healing so that the migration of all the aforesaid factors can be available more and enhance the wound healing. The main objective in wound management is to heal the wound in the shortest time possible, with minimal pain, discomfort, and scarring to the patient which is provided by the prepared hydrogel. Superior activity of the embelin containing hydrogels can be attributed to the wound healing activity of the drug itself and its established antimicrobial activity $[12,13]$. 
Table 2 Day-wise comparative healing for medicated hydrogel sheet against standard/control formulation

\begin{tabular}{|c|c|c|}
\hline Observation day & $\begin{array}{l}\text { Standard (Moisturex }{ }^{\oplus} \text { cream)/control (blank hydrogel } \\
\text { sheet) }\end{array}$ & Test (medicated hydrogel sheet) \\
\hline 3rd day post treatment & $\begin{array}{l}30-40 \% \text { reduction in wound size and presence } \\
\text { of dry scar. }\end{array}$ & $\begin{array}{l}30-40 \% \text { reduction in wound size. Additionally, absence of dry scar } \\
\text { formation, rather the wounds were moist. }\end{array}$ \\
\hline 6th day post treatment & Absence of epidermis formation. & Formation of a thin epidermis without any scar formation. \\
\hline 9th day post treatment & $\begin{array}{l}90 \% \text { reduction in wound area, but incomplete } \\
\text { epidermis formation. }\end{array}$ & $90 \%$ reduction in wound area with presence of thick epidermis layer. \\
\hline $\begin{array}{l}\text { 12th and } 15 \text { th day post } \\
\text { treatment }\end{array}$ & $\begin{array}{l}\text { Full contraction of the wound area but appearance } \\
\text { of non-uniform new skin. }\end{array}$ & $\begin{array}{l}\text { Full contraction of the wound area with appearance of new skin that } \\
\text { was uniform, cleaner and healthy. }\end{array}$ \\
\hline
\end{tabular}

\section{Conclusion}

An optimized medicated hydrogel containing $0.2 \%$ embelin (isolated, purified, and characterized) was formulated with 10\% PVA and 5\% PEG 400. The optimized formulation was further characterized by the various physico-chemical parameters like swelling index, gel fraction, water vapor transmission rate, and mechanical strength. The in vitro release studies of of the optimized formulation followed by zero order drug release kinetics with more than $80 \%$ embelin release up to $12 \mathrm{~h}$. The in vivo studies on the rats showed that the optimized embelin-loaded hydrogel is the best for initial wound healing process as it initiates the healing process faster. These encouraging results should be further explored in large scale for confirmation of in vitro parameters as well as in healthy human volunteers to prove its in vivo efficacy.

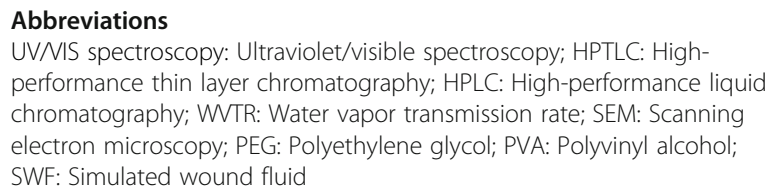

\section{Acknowledgements}

Authors are thankful to BV patel PERD Centre, Ahmedabad and NIPERAhmedabad for infrastructure and financial support. Authors are also is thankful to Department of Pharmaceuticals, Ministry of Chemicals and Fertilizers, Govt. of India for financial support to the Institute to carry out research work for Post graduate students, not specific for this project.

\section{Authors' contributions}

NS and UKM conceptualized the idea about the research work, guided the whole work, and wrote the research article. HS performed all experimental works. UKM was responsible for designing the formulation work. In vivo study was carried out under the supervision of MN. NS was responsible for data analysis. All authors read and approved the manuscript.

\section{Funding}

Not applicable

\section{Availability of data and materials}

Authors agree to provide additional data and raw materials available with us to the Journal if required.

\section{Ethics approval and consent to participate}

In vivo efficacy of the developed formulation was on Sprague-Dawley rats. Study was started after getting the approval from Institutional Animal Ethical committee (Approval No: PERD/IAEC/2010/001).

\section{Consent for publication}

Not applicable

\section{Competing interests}

The authors declare that they have no competing interests.

\section{Author details}

${ }^{1}$ National Institute of Pharmaceutical Education and Research (NIPER), Ahmedabad 380054, India. ${ }^{2}$ Department of Pharmaceutical Sciences \& Technology, Maharaja Ranjit Singh Punjab Technical University, Bathinda 151001, India. ${ }^{3}$ B.V. Patel Pharmaceutical Education and Research Development (PERD) Centre, Ahmedabad 380054, India.

Received: 13 September 2019 Accepted: 4 November 2019

Published online: 17 December 2019

\section{References}

1. Branski LK, Gauglitz GG, Herndon DN, Jeschke MG (2009) A review of gene and stem cell therapy in cutaneous wound healing. Burns 35:171-180

2. Mallefet P, Dweck AC (2008) Mechanisms involved in wound healing. Biomed Sci 52:609-615

3. Bryan J (2004) Moist wound healing: a concept that changed our practice. J Wound Care 13:227-228

4. Winter GD (1962) Formation of the scab and the rate of epithelization of superficial wounds in the skin of the young domestic pig. Nature 193:293-294

5. Vowden K, Vowden P (2017) Wound dressings: principles and practice. Surgery (Oxford) 35:489-494

6. Burd A (2007) Evaluating the use of hydrogel sheet dressings in comprehensive burn wound care. Ostomy Wound Manage 53:52-62

7. Guhabakshi DN, Sensarma P, Pal DC (2001) A lexicon medicinal plants of India. Naya Prakashan Calcutta, India, 135-136.

8. Mahendran S, Thippeswamy BS, Veerapur VP, Badami S (2011) Anticonvulsant activity of embelin isolated from Embelia ribes. Phytomedicine 18:186-188

9. Chitra M, Shyamala Devi CS, Sukumar E (2003) Antibacterial activity of embelin. Fitoterapia 74:401-403

10. Joshi R, Kamat JP, Mukherjee T (2007) Free radical scavenging reactions and antioxidant activity of embelin: biochemical and pulse radiolytic studies. Chem Biol Interact 167:125-134

11. Radhakrishnan N, Alam M (1975) Antifertility activity of embelin in albino rats. Indian J Exp Biol 13:70-71

12. Swamy HK, Krishna V, Shankarmurthy K, Rahiman BA, Mankani KL, Mahadevan KM, Harish BG, Naika HR (2007) Wound healing activity of embelin isolated from the ethanol extract of leaves of Embelia ribes Burm. J Ethnopharmacol 109:529-534

13. Radhakrishnan N, Gnanamani A, Mandal AB (2011) A potential antibacterial agent Embelin, a natural benzoquinone extracted from Embelia ribes. Biol Med 3:1-7

14. Ahmed AS, Mandal UK, Taher M (2018) PVA-PEG physically cross-linked hydrogel film as a wound dressing: experimental design and optimization. Pharm Dev Technol 23:751-760

15. Cascone MG, Maltinti S, Barbani N (1999) Effect of chitosan and dextran on the properties of poly (vinyl alcohol) hydrogels. J Mater Sci Mater Med 10: 431-435

16. Huang MH, Yang MC (2008) Evaluation of glucan/poly (vinyl alcohol) blendwound dressing using rat models. Int J Pharm 346:38-46 
17. Ajji Z, Othman I, Rosiak JM (2005) Production of hydrogel wound dressings using gamma radiation. Nucl Instrum Meth B 229:375-380

18. Kim JO, Park JK, Kim JH, Jin SG, Yong CS, Li DX, Choi JY, Woo JS, Yoo BK, Lyoo WS, Kim JA (2008) Development of polyvinyl alcohol-sodium alginate gel-matrix-based wound dressing system containing nitrofurazone. Int J Pharm 359:79-86

19. Sikareepaisan P, Ruktanonchai U, Supaphol P (2011) Preparation and characterization of asiaticoside loaded alginate films and their potential for use as effectual wound dressings. Carbohydr Polym 83:1457-1469

20. Jaiswal M, Dinda AK, Gupta A, Koul V (2010) Polycaprolactone diacrylate crosslinked biodegradable semi-interpenetrating networks of polyacrylamide and gelatine for controlled drug delivery. Biomed Mater 5: $1-13$

21. Sung JH, Hwang MR, Kim JO, Lee JH, Kim Yl, Kim JH, Chang SW, Jin SG, Kim JA, Lyoo WS, Han SS (2010) Gel characterisation and in vivo evaluation of minocycline-loaded wound dressing with enhanced wound healing using polyvinyl alcohol and chitosan. Int J Pharm 392:232-240

22. Fonder MA, Lazarus GS, Cowan DA, Aronson-Cook B, Kohli AR, Mamelak AJ (2008) Treating the chronic wound: a practical approach to the care of nonhealing wounds and wound care dressings. J Am Acad Dermatol 58: 185-206

23. Aziz Z, Abu SF, Chong NJ (2012) A systematic review of silver-containing dressings and topical silver agents used with dressings for burn wounds. Burns 38:307-318

24. MacKay D, Alan L, Miller AL (2003) Nutritional support for wound healing. Altern Med Rev 8:360-377

\section{Publisher's Note}

Springer Nature remains neutral with regard to jurisdictional claims in published maps and institutional affiliations.

\section{Submit your manuscript to a SpringerOpen ${ }^{\circ}$ journal and benefit from:}

- Convenient online submission

- Rigorous peer review

- Open access: articles freely available online

- High visibility within the field

- Retaining the copyright to your article

Submit your next manuscript at $\boldsymbol{\nabla}$ springeropen.com 